\title{
O CENTRO HISTÓRICO DE CAMPOS DOS GOYTACAZES/RJ: A REVITALIZAÇÃO, O COMÉRCIO LOCAL E A NOVA FUNCIONALIDADE DO \\ LUGAR
}

Paula Cruz Pimentel ${ }^{1}$

\section{Resumo}

A cidade de Campos dos Goytacazes situada no Norte Fluminense do Estado do Rio de Janeiro vem passando por transformações em seu espaço urbano devido ao macro projeto urbano que teve início no ano de 2011. Trata-se da revitalização do espaço urbano do centro histórico da cidade. A proposta faz parte da criação de uma 'nova economia cultural', já que a indústria petrolífera atingiu o seu auge. Nesse sentido, há uma preocupação com o futuro econômico da região e, em consequência, a tentativa de colocar em prática esta "nova economia cultural" que valoriza o que é local e presente no espaço urbano como alguns pontos históricos. Desse modo, o ensaio apresenta uma reflexão sobre os processos econômicos locais, e por último, uma discussão sobre o que vem a ser a 'nova economia cultural' que o município tenta desenvolver com as iniciativas reformistas de seu centro histórico, assim as memórias dos comerciantes locais apresentadas revelam as disputas que acontecem nesse lugar simbólico.

Palavras-chave: memória, espaço urbano, economia cultural.

\section{Abstract}

The city of Campos dos Goytacazes located in the Norte Fluminense of Rio de Janeiro state has experienced changes in its urban space due to the macro urban project that started in 2011 it is the revitalization of the urban space of the historic city center, the proposal is part of the creation of a "new cultural economy", since the oil industry reached its peak. In this sense, there is concern for the economic future of the region and, consequently, the attempt to put

${ }^{1}$ Mestre em memória social

INTRATEXTOS, Rio de Janeiro, vol. 7, n. 1, 2015, p. 1-24. ISSN 2176-6789. 
into practice this "new cultural economy "that values what is local and present in urban space as some historical sites. Thus, the essay presents a reflection on the local economic processes, and finally, a discussion of what comes to be the 'new cultural economy' that the municipality is trying to develop with the reformist initiatives of its historic center, so the memories of presented local traders reveal the disputes that take place in this symbolic place.

Keywords: memory, space urban, cultural economy 


\section{Entre o global e o local: práticas econômicas na modernidade periférica}

Este ensaio propõe desenvolver uma análise compreensiva do assunto abordado com intuito de incitar uma discussão sobre as práticas econômicas desenvolvidas no município de Campos/RJ. Nota-se uma articulação estratégica de uma política cultural municipal e o comércio local que frisam um discurso aonde se destaca uma memória regional com a intenção de inserção no contexto nacional econômico, o que leva a suscitar o debate entre o local e o global, visto que tais iniciativas, aqui, se encontram atreladas ao grupo dos empresários. A pergunta que se pretende responder no final deste ensaio é: de que maneira o local, no caso, Campos/RJ, vem desenvolvendo suas práticas econômicas?

Não se pode deixar de fora desta discussão a problemática que esta região vive nos dias atuais. Campos/RJ sempre esteve envolvida na promessa de um desenvolvimento econômico próspero, durante as três primeiras décadas do século XX chegou ao auge com a produção do açúcar e se destacou nacionalmente. Após a falência dos engenhos de açúcar em1940, no ano de 1978se iniciou uma nova atividade econômica graças à descoberta do petróleo, e consequentemente o 'boom' da indústria petrolífera, porém a cidade perdeu sua posição de destaque para a cidade vizinha, Macaé, que passou a vivenciar o crescimento urbano e econômico inesperado.

A economia petrolífera abriu vagas de emprego na área tecnológica e fez alavancar os cursos técnicos profissionalizantes, mas ainda não foi suficiente para que houvesse grandes mudanças tanto sociais quanto infraestruturais da cidade, se tratando de um modelo econômico excludente. A promessa de um milagre desenvolvimentista permaneceu no imaginário local e hoje se resume em frustração por parte dos habitantes que se encontram sem alternativas no mercado de trabalho. A expectativa da população era apostada na possibilidade da vinda de grandes indústrias, o que não aconteceu.

O território Norte Fluminense passou por uma rápida mudança que afetou toda a região.A importância econômica do Norte Fluminense é reconhecida nacionalmente, porém a economia local aponta para uma estagnação, mesmo contando com o recurso dos royalties ${ }^{2} \mathrm{em}$ sua receita que possibilita o investimento em outros setores da economia. Ao tomar ciência

\footnotetext{
${ }^{2} \mathrm{O}$ Royalty é um recurso financeiro destinado aos municípios que possuem plataformas marítimas em operação e tem objetivo compensatório já que se trata de um recurso esgotável e de impacto ambiental.
} 
destes fatores fica claro que existe uma articulação de estratégias entre as elites empresariais e as figuras políticas que possibilitaram recentes incentivos a uma revitalização do centro histórico com objetivos de movimentar a economia da cidade tentando valorizar os seus espaços vitais. O espaço urbano do centro histórico de Campos/RJ é um lugar em contínua transformação que apresenta uma série de conflitos e disputas neste território - de um lado os que ali desenvolvem as suas atividades comerciais: os comerciantes tradicionais presentes há mais de quarenta anos, de outro lado, as iniciativas municipais que tentam revitalizar o espaço urbano com obras que modificam os lugares de memória e identidade dos habitantes.

Os pequenos comerciantes estabelecidos no centro da cidade estão vivenciando uma grande transformação - o embate da força avassaladora do capital transnacional que transforma as relações de nível local e tentam acompanhar um modelo de economia global e vão de encontro aos anseios das iniciativas municipais que desejam um novo cenário econômico que possa incluir Campos num contexto de cidades competitivas e globalizadas.A construção de novos shoppings centers símbolos modernos da sociedade de consumo foi um dos fatores que levaram a uma nova funcionalidade do centro histórico da cidade de Campos, aliado a isso a nova propulsão do mercado transnacional na economia local que assume o caráter de uma concorrência desleal e avassaladora.

Para que o leitor compreenda os nuances presentes neste espaço de sociabilidades descrevo a seguir alguns trechos das entrevistas que foram realizadas com os comerciantes locais do centro histórico da cidade, as entrevistas narram diversos percursos de memórias em que o individuo caminha pela cidade em uma paisagem extremamente fragmentada.O filósofo alemão George Simmel em sua obra "As Grandes Cidades e a Vida do Espírito" (1903), retratou o espaço urbano como um ambiente que estimula os sentidos nervosos, aquilo que o autor definiu como "caráter blasé", a indiferença diante de tudo e de todos. Este seria o novo desafio para o homem que tem de enfrentar os novos moldes modernos, tanto econômicos quanto sociais, em que o individuo busca sentido para essas rápidas transformações.

As narrativas como método de estudo podem partir de um estudo micro, ou seja, de um determinado mundo social para revelar questões de ordem macro, como problemas sociais, costumes, crises econômicas, violência urbana, pertencimento identitário e outros temas que os interlocutores expõem em suas narrativas. Como assinalam as antropólogas Ana Luisa Carvalho da Rocha e Cornelia Eckert: 
"Os espaços urbanos construídos e vividos como objeto do estudo etnográfico vão se revelando não meros reflexos de políticas urbanísticas, mas suportes de tradições biográficas de seus habitantes, cujas narrativas expressam uma linguagem coletiva que comunica uma pluralidade de identidades e memórias. As experiências em suas trajetórias são interpretadas e comunicadas na forma narrativa. Neste tempo do jogo da memória, a forma narrativa agencia os fatos em intrigas reconfiguradas para interpretação dos interlocutores que integram na condição pública com a memória compartilhada",

Podemos compreender que as memórias sobre o centro histórico de Campos são interpretadas por seus interlocutores e expressam a ligação com esse lugar.Como afirmou Michel Pollack "a memória é um elemento constituinte do sentimento de identidade (1992:5), mas, as reconfigurações em conseqüência de recorrentes intervenções urbanas também realizam transformações nessas memórias, com isso estão sempre sendo atualizadas.A memória é mutável. O mundo moderno renovou seus suportes de tradições. A metáfora do flanêur utilizada por Walter Benjamin ${ }^{4}$ sobre o poeta Baudelaire e a relação com a cidade de Paris, daquele que caminha pela cidade procurando sentido nas novas experiências de uma paisagem fragmentada, traduz bem essa sensação de algo que se perdeu com a aceleração do tempo e da informação. Os percursos de memórias narrados sobre o centro histórico de Campos nos transportam para outro tempo, a paisagem urbana é interpretada pelos usuários do espaço de maneira híbrida com referências de um tempo passado e um tempo presente.

\section{Memórias de comerciantes locais do centro histórico de Campos/RJ}

\footnotetext{
"Acidade moderna, em mudança, é, sobretudo, uma praça de comércio e deve sua existência ao mercado ao redor da qual se desenvolve. A competência industrial e a divisão do trabalho, que com toda a probabilidade tem contribuído em grande medida ao desenvolvimento das energias latentes da humanidade, só são possíveis pela existência dos mercados, do dinheiro e de outros meios que facilitam os negócios e o comércio”.(PARK,1999,57)
}

A parte central da cidade de Campos se caracteriza pelo intenso movimento comercial, o fluxo de carros nas ruas e de pessoas, nas estreitas calçadas. Ao caminhar pelo centro de olhos atentos ao que se passa ao redor encontramos uma cidade viva e pulsante, as calçadas estreitas cheias de gente indo e vindo a todo o momento. As lojas do centro, em geral são lojas mais populares e de preço acessível, com isso atraem uma determinada classe social, em 
geral, estão distribuídas nessa área central, e abrem suas portas logo pela manhã, entre oito e nove horas.

É bastante comum ir ao centro para resolver problemas rotineiros da vida social, pela facilidade que existe na concentração de diversos mercados numa mesma área: o mercado municipal, o camelódromo e as ruas aos arredores com seus comércios lojistas, todos fazem parte da área central, porém com diferenças pontuais entre os comerciantes "os camelôs se diferenciam dos demais comerciantes da cidade, no caso, os lojistas, pela situação jurídica de sua ocupação, uma vez que não é o dono de seu espaço de trabalho, que é cedido pelo poder público, no caso, municipal ${ }^{5,}$.

Ainda pelo centro da cidade na Avenida Alberto Torres está localizado o terminal de parada obrigatória dos ônibus que circulam pela cidade,de um lado a bela paisagem do rio Paraíba, e do outro lado à cinzenta Praça São Salvador que foi reformada entre 2004 e 2005. Antes da reforma a Praça tinha uma paisagem verde da grama e das árvores, a reforma não agradou a maioria da população que não se identifica com o novo cartão postal da cidade, cinza, sem sombra e escorregadia em dias chuvosos, a nova repaginada custou 46 milhões e provocou indignação a população.A praça se transformou em lugar de passagem, os habitantes lamentam com sentimento nostálgico do antigo espaço que fazia uso frequente, era um ambiente de sociabilidades e hoje apenas palco para shows gratuitos à noite e passagem de pedestres durante o dia. É verdade que outras práticas sociais vão sendo incorporadas neste espaço como a apropriação da praça pelas performances dos skatistas, mas os usos desse espaço público antes de sua última reforma ainda é lembrado de maneira nostálgica entre os habitantes. Em uma conversa informal com o comerciante Mário ${ }^{6}, 53$ anos, que me relatou que apesar de terem se passado dez anos, ainda sente saudade da antiga Praça:

"Essas obras fizeram do centro uma bagunça, isso tudo pra ganhar as eleições, porque só quem tem o seu comércio no centro sabe os transtornos que passamos, e esta Praça não tem nada a ver com o povo, nem com a cidade. Antigamente víamos a qualquer hora do dia os bancos ocupados, e as árvores dava uma sombra boa. (...) Eu penso também que essa revitalização das ruas, edifícios e estabelecimentos tem a intenção de movimentar mais a economia local, isso é o interesse de algumas pessoas",7.

\footnotetext{
${ }^{5}$ ASSIS: 2011: 37

${ }^{6}$ Com intuito de preservar a identidade dos informantes os nomes foram alterados.

${ }^{7}$ Mário em entrevista concedida.
} 
Em seu relator Mário chama atenção para a falta de humanização dos espaços a Praça perdeu significado que lhe conferiam, mas isso não significa que não possam surgir novos significados em decorrência das práticas sociais. Seu relato evidencia a estranheza das recentes obras no centro da cidade, e fica a desconfiança da intencionalidade do projeto urbano que traz a modernidade pros espaços, porém tem de conviver com o tradicional. Assim, a identidade cultural se define baseada nas novas histórias que podem surgir e que conferem novos significados aos lugares. Ao caminhar pelo centro de Campos, espaço de efervescência econômica, social e política, observei não só pessoas apressadas, mas a organização física daquele espaço que foi construído por práticas sociais. As lojas estão organizadas lado a lado, a Praça São Salvador, considerada o lugar de referência da cidade, lugar de memória e espaço simbólico. A igreja do Santíssimo Salvador está localizada em frente à Praça São Salvador, aos domingos de manhã agrega fiéis para assistirem a missa, Ana Lúcia,48 anos, moradora e usuária do espaço relata que "o centro sempre foi visto com maus olhos, poucas pessoas vem pra cá passear a noite, isso fica um deserto, é perigoso! " ".A utilidade desse espaço é caracterizada pela atividade comercial, a noite há pouca movimentação e dependendo do horário, não há mais ninguém. O Mercado Público acorda cedo, de madrugada para dar início às vendas, é preciso deixar tudo preparado e organizado, os caminhões então descarregam e os feirantes são os primeiros a abrirem.Próximo a Praça existe uma floricultura aberta durante o dia, mas seu diferencial é que ao entardecer, entre as 5 e 6 horas, se torna um espaço de lazer, homens se reúnem para jogar carta e tomar cerveja. Colocam uma mesa e algumas cadeiras e ali entre um jogo e outro gritam, riem e se divertem como se aquele espaço fosse privado. Nada tira a atenção daqueles que estão jogando nem as pessoas que passam, olham, comentam e seguem. Às seis da tarde algumas lojas começam a fechar, e as ruas perdem o movimento. O comerciante José, 30 anos, relata que os comerciantes da área vêm reclamando por causa do lucro que já não é o mesmo e caiu nos últimos anos, isso se deve ao novo shopping construído na cidade relata ele :

"Alguns clientes passaram a fazer compras à noite, porque o shopping está aberto esse horário e é um lugar seguro e bem cuidado".

\footnotetext{
${ }^{8}$ Ana Lúcia em entrevista concedida.

${ }^{9}$ José em entrevista concedida.
} 
Os frequentadores do centro de Campos reclamam dos roubos que acontecem frequentemente, o que faz do lugar uma área insegura, com pouco policiamento. Quando indaguei o Senhor José sobre a intencionalidade da revitalização, não se prolongou e afirmou:

\begin{abstract}
"Querem transformar o centro numa Pelinca ${ }^{10}$, que é muito mais bem cuidada. Agora é só shopping na cidade. Onde era o campo do Americano na Avenida 28 de Março vão construir um novo shopping. Vão fazer um monte de coisa lá. Residência e shopping e isso só vai afastando o povo do centro" $" 11$.
\end{abstract}

Nas falas podemos notar que os comerciantes entrevistados nesse estudo sentem uma nostalgia de uma época em que o centro era o único pólo concentrador da vida social campista, José relatou sobre esse deslocamento do público consumidor do centro que hoje passou a ir mais aos shoppings pela diversidade de serviços que eles concentram. Outro fator importante a ser considerado é a mudança do perfil dos consumidores, entre os anos de 30-70 havia uma agroindústria do açúcar que concentrava a riqueza do município, mas com a falência das grandes usinas da cidade e o advento da economia petrolífera o perfil da elite local também mudou a cidade passa a ter outra forma de concentração de riqueza, o centro da cidade então muda de funcionalidade em conseqüência do crescimento da cidade,o nascimento do segundo centro comercial da cidade o bairro nobre da Pelinca seria um dos motivos para essa mudança de funcionalidade do centro. $\mathrm{O}$ bairro Pelinca dá continuidade ao bairro do centro, possui uma estrutura de bancos, shoppings, restaurantes, casas noturnas e bares, outro fator são os shoppings centers que vão sendo construídos espalhados pela cidade.

O tecido urbano central possui diversos comércios populares espalhados pelas ruas principais e em torno da Praça São Salvador, mas é no Bairro Pelinca que estão os novos shoppings centers e as lojas mais modernas e refinadas que são frequentadas pela classe média e classe média alta. Podemos notar o contraste das características entre o comércio tradicional e o comércio moderno. Os comércios modernos são aqueles que investem na estética de suas lojas e na tecnologia informática, os comércios tradicionais são mais simples, uns até possuem computadores, mas suas mercadorias ficam de maneira desorganizada nas prateleiras, como se estivessem amontoadas, são pequenas casas comerciais, muito dessas

\footnotetext{
${ }^{10} \mathrm{O}$ bairro Pelinca é o outro pólo comercial da cidade mais novo é um bairro que possui bancos, bares, cafés, edifícios luxuosos e shoppings centers. É considerado um bairro de classe média alta com uma vida noturna agitada.

${ }^{11}$ José em entrevista concedida.
} 
lojas comerciais são prédios e casas antigos e estão em estado degradante precisando de reformas. O colorido das mercadorias penduradas para fora das lojas, as ruas estreitas e as calçadas amontoadas de pessoas é o contrário do que acontece no centro comercial do bairro Pelinca - as ruas são largas, as pessoas bem arrumadas, muitas usam salto alto e maquiagem, vão para passear, fazer compras em lojas de classe média. No centro comercial do centro da cidade notamos um vai e vem tumultuado, próximo ao mercado municipal um churrasquinho popular com mesinhas onde as pessoas param para fazer um lanche e tomar uma cerveja tendo como distração a música no rádio que é sempre muito animada. O comerciante Ronaldo proprietário da livraria mais antiga do Brasil "Ao livro Verde" se lembra da época em que a prosperidade econômica do município ia bem e a sua clientela privilegiada eram os usineiros, mas com o declínio da produção do açúcar todos na cidade que sobrevive do comércio saíram perdendo, relata:

As usinas de Campos fecharam todas! Nós vendíamos pra todas as usinas!Fornecíamos material escolar. Separávamos uns dez funcionários só pra atender o pessoal das usinas, mas nós perdemos isso! E todos perderam com isso, agora só restam duas ou três usinas no máximo ${ }^{12}$.

\section{Quando a economia é a cultura: o centro histórico como patrimônio cultural}

Nos veículos de comunicação midiáticos como: o rádio, a TV, a internet, e o jornal local nota-se a presença de um discurso que valoriza as ações políticas culturais desenvolvidas na cidade de Campos dos Goytacazes/RJ. Neste caso, é relevante se atentar também para o envolvimento e apoio que o comércio local dá as ações políticas culturais do município. $\mathrm{Na}$ esfera política quando o assunto é a transformação do espaço urbano da cidade o discurso aparece sempre vinculado a:"tradição", "modernização", "desenvolvimento econômico", "patrimônio cultural" e "memória regional". Para tanto, durante a exposição da problemática tratada recorro a relatos divulgados na imprensa local, não apenas pela influencia dos veículos de comunicação na opinião pública, mas se faz necessário uma breve análise dos discursos recorrentes sobre a cidade. Nesse sentido, Néstor Canclini (2002) chama atenção para a influência dos relatos apresentados na mídia ao legitimarem os lugares de pertencimento:

${ }^{12}$ Ronaldo em entrevista concedida. 
Os relatos mais influentes sobre o que significa a cidade emergem agora da imprensa, do rádio e da televisão. No tumulto heterogêneo e disperso de signos de identificação e referência, os meios não propõem tanto uma nova ordem, mas sim oferecem um espetáculo reconfortante. Mais do que estabelecer novos lugares de pertencimento e de identificação de raízes, o importante para as mídias é oferecer certa intensidade de experiências (CANCLINI, 2002:3).

O que se atenta nos discursos é a exaltação de um patrimônio cultural que afirma uma identidade local com a intenção de obterem vantagens econômicas ao investir no mercado turístico. Para tanto, apresento neste último tópico a ênfase que o município dá ao discurso de uma memória local e de como esse discurso é colocado em prática como um argumento para a aplicação de políticas públicas municipais que vêem sendo colocada em prática com objetivo de fazer alterações neste espaço urbano importante como o centro histórico da cidade, um lugar simbólico dotado de memórias afetivas. Com o propósito de incitar uma discussão sobre o que vem a ser a 'nova economia' e porque de tal aposta em investimentos em um novo setor econômico, o turismo, que visa expandir os lucros municipais.A intenção de realizar a revitalização do centro histórico com o macro projeto acontece desde o ano de 2011, isso nos chama a atenção para pensar na importância do espaço urbano para os habitantes e para os que são especificamente afetados por essas transformações - os comerciantes locais. As iniciativas municipais querem legitimar a importância do centro histórico para a cidade,algumas áreas em especial estão no projeto para serem reformadas estes espaços urbanos são os lugares de memória para os habitantes da cidade.

Os antropólogos Arno Vogel e Marco Antonio de Mello no artigo "Sistemas construídos e memória social: Uma arqueologia Urbana?” (1984) propõem o conceito de uma "arqueologia urbana" que seria um processo de escavação da cidade por meio de narrativas espaciais, a estrutura material da cidade esconde diversos tempos, nesse sentido a paisagem urbana é extremamente fragmentada e podemos notar isso nos percursos memoriais apresentados nesse estudo sobre o centro da cidade e compreenderemos como os usuários desse espaço enxergam as intervenções urbanísticas no seu cotidiano com a relação que desenvolvem com a cidade, para o mundo social dos pequenos comerciantes o que já se tornou memorável mesmo não estando mais ali materialmente? As narrativas memoriais podem revelar não apenas um suporte material, mas as estórias que se escondem por de trás de cada prédio, rua, beco, casa, comércio e, sobretudo, nos apresentam a vida social do lugar. 
Por isso o os sistemas construídos e reconstruídos só seriam possíveis com as práticas sociais que configuram o espaço urbano, esclarecem os antropólogos Mello e Vogel:

\begin{abstract}
“As cidades são verdadeiros sistemas de memórias, sistemas construídos que o animam, constituem uma unidade em tensão e em processo. Ao mesmo tempo, apresentam-se como uma espécie de arquivo de modo de viver que os concebeu e como agência produtora de novos modos de vida. Arquivo em permanente processo de atualização, portanto. Nele, os princípios, as idéias e as relações característica de uma determinada sociedade, além de se inscreverem materialmente, podem ser apreendidos de forma sintética ${ }^{13}$,
\end{abstract}

O centro da cidade de Campos nos últimos anos vem passando por diversas transformações, a primeira etapa do macro projeto urbanístico foi inaugurada no dia 10 de maio de 2013. Os jornais locais anunciaram o evento como importante passo para a modernização da cidade, visto que o projeto de revitalização do espaço central tem remodelado alguns pontos. Dessa maneira, a atividade turística, no momento, está sendo colocada em questão em consequência do enfoque dado a uma "economia cultural" "que se encontra em vigência no município. O sentido conferido à cultura que estrategicamente e de modo conveniente é utilizada como um recurso a "iniciativas para promover a utilidade sociopolítica e econômica" ${ }^{15}$.É interessante pontuar que a revitalização do centro suscita algumas questões a serem problematizadas:

\footnotetext{
"O comércio deverá seguir o novo padrão da regulamentação e normatização do Centro Histórico de Campos, que inclui a retirada de marquises e letreiros que agridam a paisagem urbana, recuperando o cenário histórico do local. A beleza arquitetônica dos prédios está escondida atrás dos letreiros. Segundo a nova regulamentação, os prédios não poderão ser envelopados ou escondidos por uma questão técnica, as lojas deverão evitar o gotejamento nas calçadas, a pintura deverá ser em tinta pastel, entre outras normas exigidas. O trabalho está sendo feito junto às lideranças da Câmara de Dirigentes Lojistas (CDL), Cajorpa e Associação do Comércio e Indústria de Campos - explicou Orávio" 16 .
}

As normas impostas aos comerciantes parece se tratar de uma cartilha de regras com objetivo de tornar o centro mais atrativo a que vem de fora. Diversas obras já foram realizadas, a reforma da Praça Prudente de Moraes, conhecida como Chá Chá Chá, a reforma

\footnotetext{
${ }^{13}$ Vogel e Mello: 1984:6

${ }^{14}$ Termo desenvolvido por George Yúdice em "A Conveniência da Cultura” (2006)

${ }^{15}$ YÚDICE: 2006: 34

16 Trecho da entrevista concedida a matéria do portal da prefeitura de Campos http://www.campos.rj.gov.br/exibirNoticia.php?id_noticia=18856
} 
da rodoviária do centro, a restauração do Solar do Visconde de Araruama que hoje funciona o Museu Histórico de Campos, a revitalização do Canal Campos-Macaé, mais conhecido como Beira Valão, a recuperação do Monumento ao Expedicionário localizado na Praça São Salvador, a construção da Praça de Alimentação e a quadra de basquete sob a ponte Leonel de Moura Brizola. A prefeitura ainda promete outras obras que incluem: a reforma do Shopping Popular Michell Hadad e do Mercado Municipal, e a recuperação do chafariz belga da Praça Quatro Jornadas.Mas, o que pensa a população sobre esse novo modelo de cidade imposta? Os habitantes se questionam sobre as intenções das obras, uns dizem que é uma maneira de garantir a próxima eleição, outros relatam que há um único interesse: o econômico, tornar a cidade atrativa para o mercado turístico. Há uma preocupação estética, de forma que tentam organizar o espaço encobrindo fios e placas de propagandas:

"De acordo com o presidente do Conselho de Preservação do Patrimônio Municipal (COPPAM), Orávio de Campos, o grupo de trabalho que trata das obras do Centro Histórico está realizando estudos, no sentido de retirar a poluição visual dos prédios localizados no perímetro do centro" ${ }^{\text {"17 }}$.

O macro projeto urbano do centro está sendo imposto sem um diálogo com a sociedade, o receio agora é do que está por vir com a reforma do Camelódromo e do Mercado.No entanto, a hipótese de que este novo investimento no mercado turístico é uma maneira de se apegar a uma alternativa de desenvolvimento econômico no Município depois do fracasso do Porto do Açu ${ }^{18}$ que era visto como a chegada de um progresso econômico para toda a região Norte Fluminense não deve ser descartada. No ano passado foi lançado um inventario turístico da cidade que está presente no novo portal turístico, o site possui informações sobre as atividades turísticas, essas iniciativas ressaltam os investimentos visando a intencionalidade de se desenvolver uma nova economia. É evidente o objetivo de tais ações quando a prefeita Rosinha Garotinho declarou a imprensa:

"Estamos oferecendo uma gestão mais moderna no turismo. As pessoas vão se surpreender. Vamos criar uma nova economia na nossa cidade, pois o turismo traz recursos ${ }^{19,}$.

17 Trecho de uma matéria jornalística extraída do site: http://www.campos.rj.gov.br/exibirNoticia.php?id_noticia=18856

${ }^{18}$ O Porto do Açu é um empreendimento logístico da empresa LLX controlado pelo bilionário Eike Batista. ${ }^{19}$ Trecho de uma matéria extraída do site: http://www.campos.rj.gov.br/exibirNoticia.php?id_noticia=18786 
Com isso, sem dúvida, se pode ligar o evento das obras do centro ao novo plano econômico cultural que tem objetivo de melhorar o espaço do centro da cidade e consequentemente aumentarem os lucros comerciais com o discurso de estar patrocinando a preservação do patrimônio cultural. Também fica evidente o apoio de alguns empresários, o presidente da Carjopa (Associação dos Comerciantes e Amigos da Rua João Pessoa e Adjacências), Eduardo Chacur que se pronunciou dizendo que "a área central se tornará um shopping a céu aberto”.

Os apontamentos tratados neste artigo ilustram a temática proposta: a problemática da revitalização do espaço urbano em Campos dos Goytacazes que vem se processando nos últimos anos. Este evento envolve diversos atores - os comerciantes, os políticos e os habitantes, cada um com seus interesses específicos. O macro projeto urbano em desenvolvimento, a todo vapor, tem um custo de quase 65 milhões ${ }^{20}$ e ainda é apresentado pelos seus idealizadores como sendo um grande passo para o bem estar da população. Mas para os habitantes há uma grande controvérsia, se tratando de problemas urbanos a pauta do funcionamento do transporte coletivo ${ }^{21}$ há tempos é reivindicada pela população, os ônibus são em sua maioria sucateados e a longa espera no ponto de ônibus comprova a ineficácia do sistema. Isso demonstra que as reivindicações dos habitantes e da política local são distintas no que diz respeito à revitalização do centro; fica claro que a iniciativa reformista está sendo sustentada por um determinado interesse econômico, político e social.

Este estudo evidencia a temática da memória e do patrimônio como uma questão que permeia o projeto de revitalização e está presente no discurso de preservação do patrimônio cultural dos bens materiais presentes no espaço central da cidade em que é frequentemente usado para garantir a legitimação ${ }^{22}$ das obras, principalmente como justificativa de gastos públicos. Além disso, o espaço sofre alterações que nem sempre pensa em seus usuários, como por exemplo, a praça principal da cidade em que os habitantes não se identificam, há por trás dessa mudança um processo amplo que resulta em uma crise de identidade. Nesse sentido Stuart Hall define a crise como um amplo processo:

A assim chamada "crise de identidade" é vista como parte de um processo mais amplo de mudança, que está deslocando as estruturas e processos

\footnotetext{
${ }^{20}$ http://www.campos.rj.gov.br/exibirNoticia.php?id_noticia=24415

${ }^{21}$ http://g1.globo.com/rj/norte-fluminense/noticia/2014/05/licitacao-do-transporte-publico-de-campos-rj-recebetres-propostas.html

${ }^{22}$ http://portal.iff.edu.br/campus/campos-centro/noticias/revitalizacao-de-centro-historico-e-tema-de-palestra 
centrais das sociedades modernas e abalando os quadros de referência que davam aos indivíduos uma ancoragem estável no mundo social ${ }^{23}$.

O discurso do presidente da Associação dos Comerciantes evidencia que os comerciantes que apóiam a revitalização anseiam por um novo espaço moderno que reanime a economia local da cidade, mas em contrapartida não há uma diretriz municipal no sentido de tentar amenizar as perdas simbólicas para os usuários desse espaço.

Este sucinto artigo apresentado é um fragmento de minha pesquisa realizada no programa de pós-graduação em memória social da Universidade Federal do Estado do Rio de Janeiro e teve como tema a memória do centro histórico da cidade de Campos, é de se destacar os conflitos que envolvem a revitalização deste espaço urbano e que aparecem nitidamente nas narrativas memoriais dos pequenos comerciantes campistas, no estudo desenvolvido entrevistei cinco comerciantes locais que estão a quarenta anos trabalhando no comércio da cidade, sendo que utilizei três entrevistas para a dissertação, as entrevistas realizadas foram pautadas no método da história de vida da clássica obra do sociólogo Daniel Bertaux "Los relatos de vida" (2005).

A obra "A memória coletiva" (1990) de Maurice Halbwachs também contribuiu para o formato da pesquisa, Halbwachs afirma que as imagens espaciais desempenham um importante papel na memória coletiva, nesse sentido o historiador Michel de Certau também dá destaque para os relatos citadinos afirmando em sua obra "A invenção do cotidiano" (1980), que os relatos sobre a cidade podem mostrar aquilo que não existe mais, porém já se tornou memorável, afirma:

Os lugares são histórias fragmentadas e isoladas em si, dos passados roubados à legibilidade por outro, tempos empilhados que podem se desdobrar, mas que estão ali antes como histórias à espera e permanecem no estado de quebra-cabeças, enigmas, enfim simbolizações enquistadas na dor ou no prazer do corpo ${ }^{24}$.

Apesar das iniciativas e estratégias de intervenções urbanas por parte das gestões municipais com desejo de melhorar e modernizar a área central da cidade de Campos, o que se observa nos relatos dos entrevistados é uma recorrente nostalgia pelas perdas impetradas pelas modernizações urbanas o que Stuart Hall chama de "crise de identidade" em que os

\footnotetext{
${ }^{23}$ HALL: 2012:07

${ }^{24}$ CERTAU: $1994: 189$
} 
quadros de memórias espaciais são abalados pelas transformações urbanas que visam dotar a cidade de elementos modernos. Segundo os interlocutores que participaram da pesquisa muitos comércios têm entrado em estado de falência devido à concorrência e à nova maneira de se fazer comércio, mais moderna e competitiva. A mudança de público também é perceptível e em decorrência do crescimento da cidade o comércio se dividiu entre os dois pólos - o bairro pelinca e o bairro central da cidade. Os fatores como o aumento da violência urbana, a especulação imobiliária, a ausência de uma política pública que possa revitalizar a área pensando em seus usuários são elementos apontados como agravantes da situação atual do centro histórico de Campos/RJ.

Podemos notar que há nas recordações memoriais dos comerciantes locais um sentimento nostálgico que se traduz para este grupo como um desprestígio em consequiência da mudança de funcionalidade do centro da cidade que até os anos 70 era considerado o único lugar que oferecia variados tipos de serviços. É de se destacar que ainda hoje o centro histórico é um lugar de memória e identidade, mas devido aos novos elementos modernos que foram incorporados pela cidade interiorana o centro histórico assumiu uma nova maneira de se relacionar com a cidade, já não concentra a vida social política e econômica, mas ainda é um importante lugar de memória e identidade para seus habitantes possuindo uma paisagem híbrida que convive com novos e antigos elementos que dão suportes materiais às memórias afetivas dos habitantes - de solares urbanos de barões e viscondes a modernos prédios comerciais e shoppings centers. 


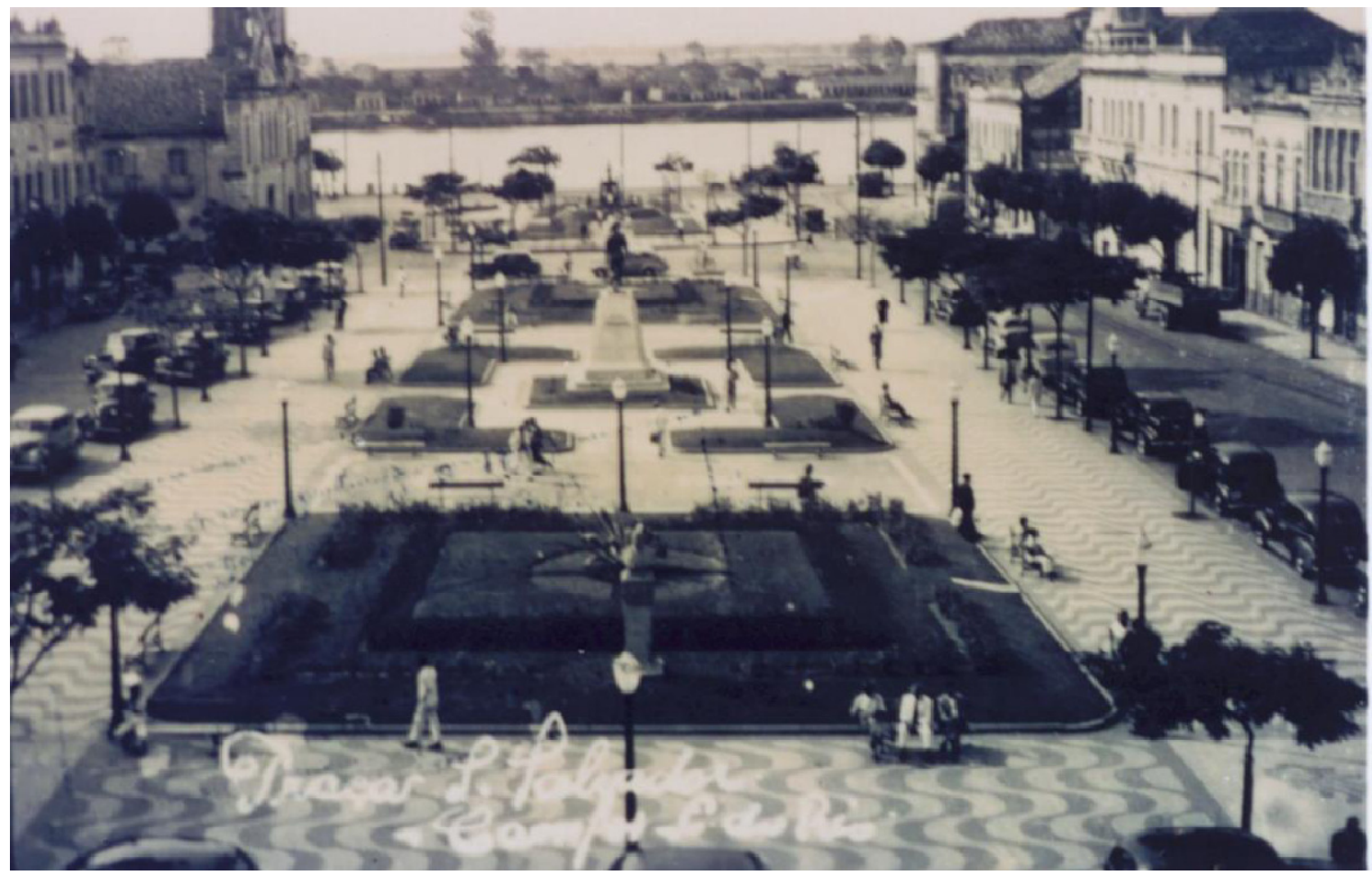

Imagem 01: A Praça São Salvador na década de 60 já com ares de modernidade, o Rio Paraíba do Sul ao fundo e à esquerda o prédio da Santa Casa de Misericórdia ainda presente na paisagem.Fonte: Arquivo Público de Campos. 


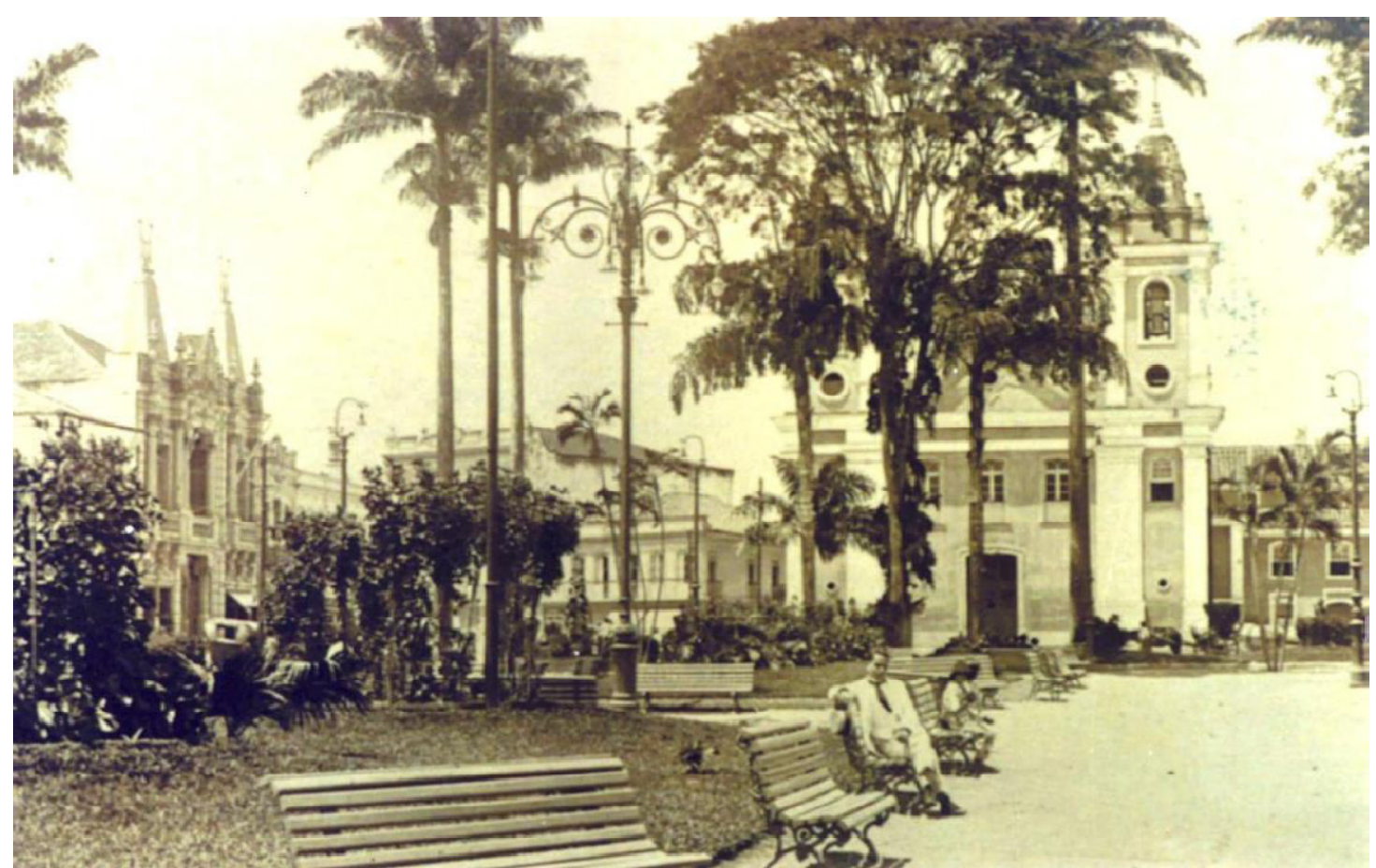

Imagem 02: A Praça São Salvador, ao fundo a Catedral e à esquerda a escola de música Lirade Apollo.Fonte: http://institutohistoriar.blogspot.com.br/2013/03/ha-178-anos-atrascampos-dos-goytacazes.ht

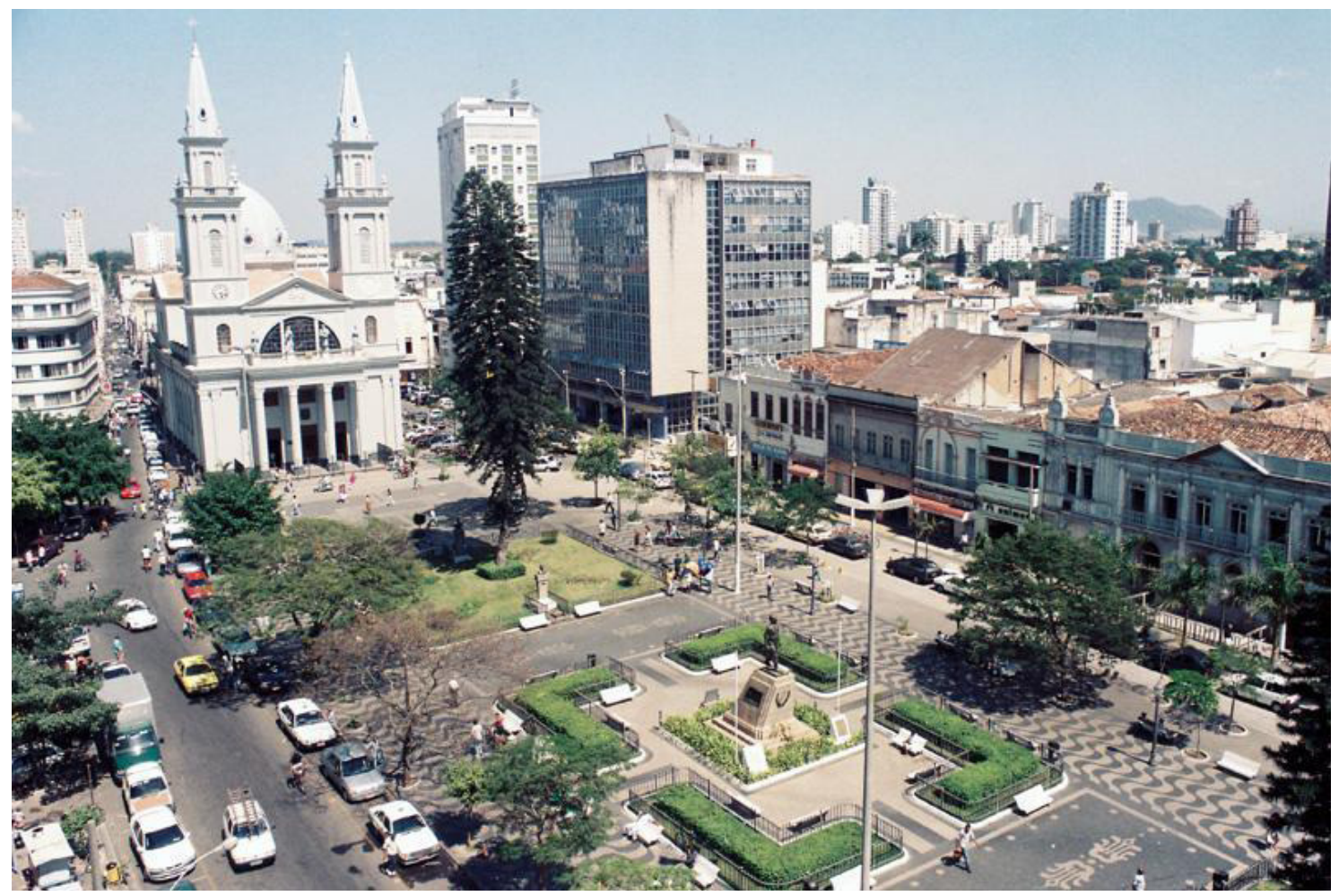

Imagem 03: A Praça São Salvador antes da última reforma em 2011. Fonte: http://ideias.org.br/informativo/campos-dos-goytacazes-inicia-inventariacao-turisticaemjaneiro 


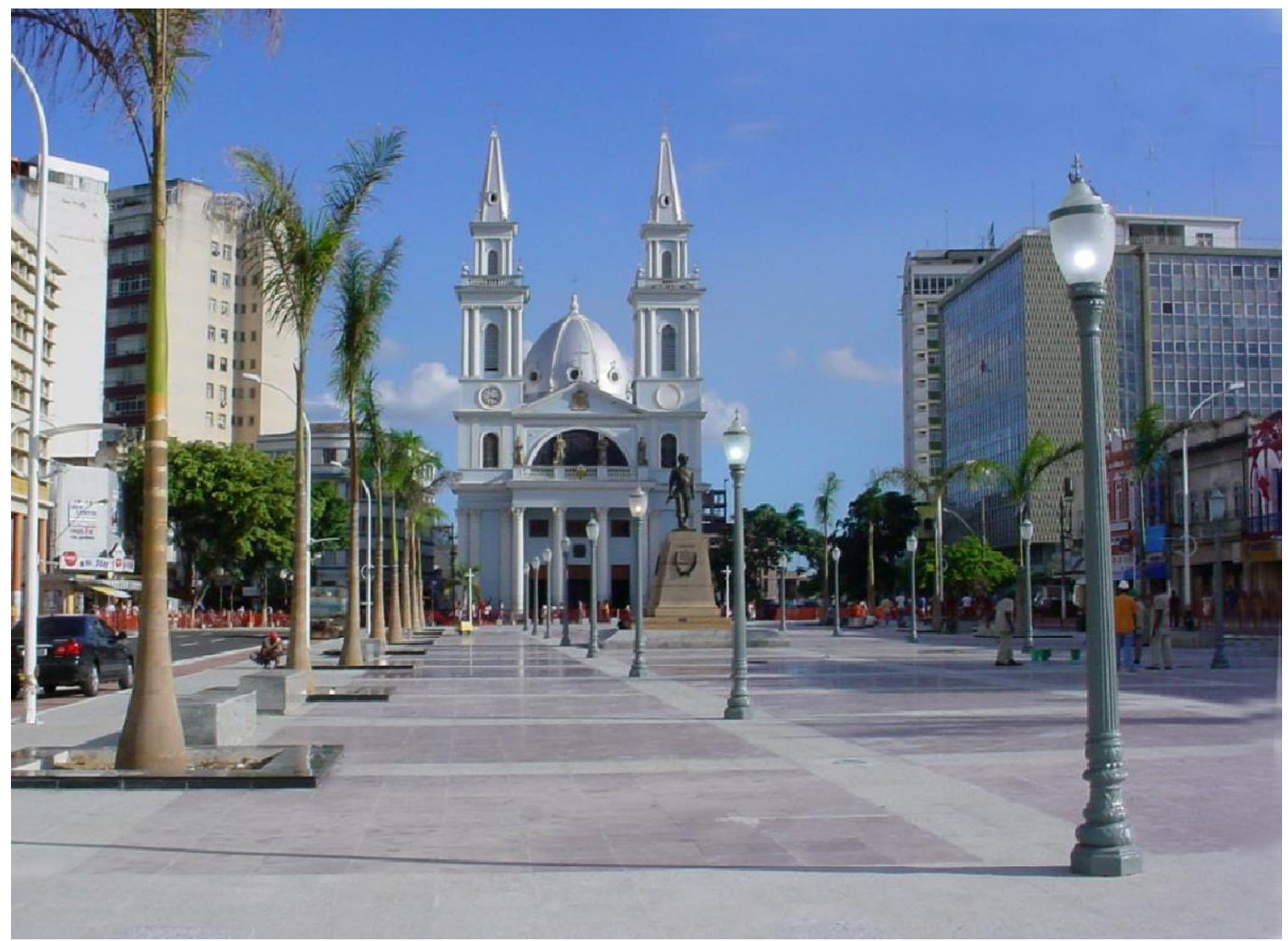

Imagem 04: A Praça São Salvador depois da última reforma, com o calçamento em mármore $e$ as árvores foram substituídas por palmeiras reais. Fonte: http://institutohistoriar.blogspot.com.br/2010/03/elevacao-de-campos-dos-goytacazes.html 


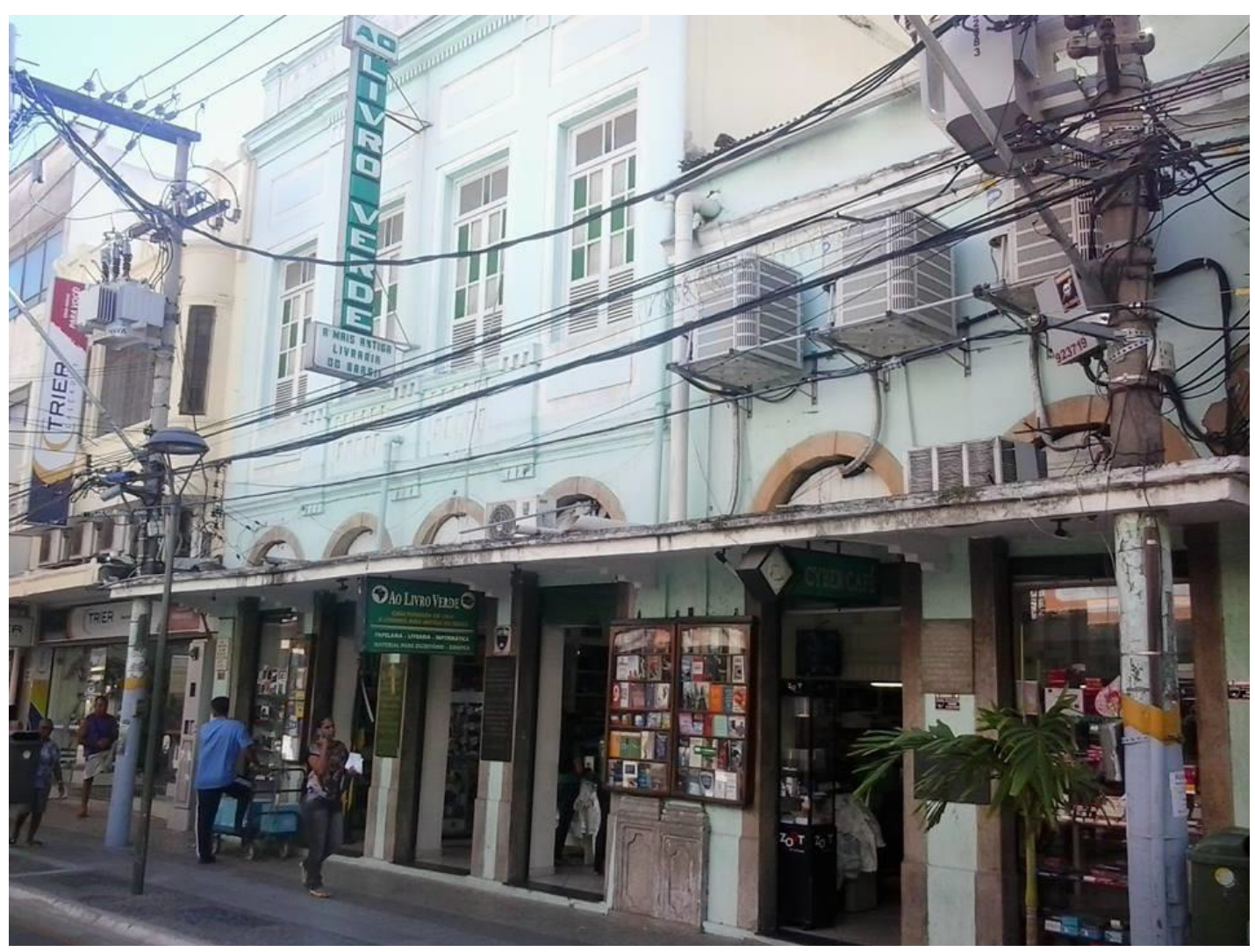

Imagem 05: O Prédio da Livraria "Ao Livro Verde”, situada na Rua Vinte e Um de Abril Foto: Paula Pimentel 


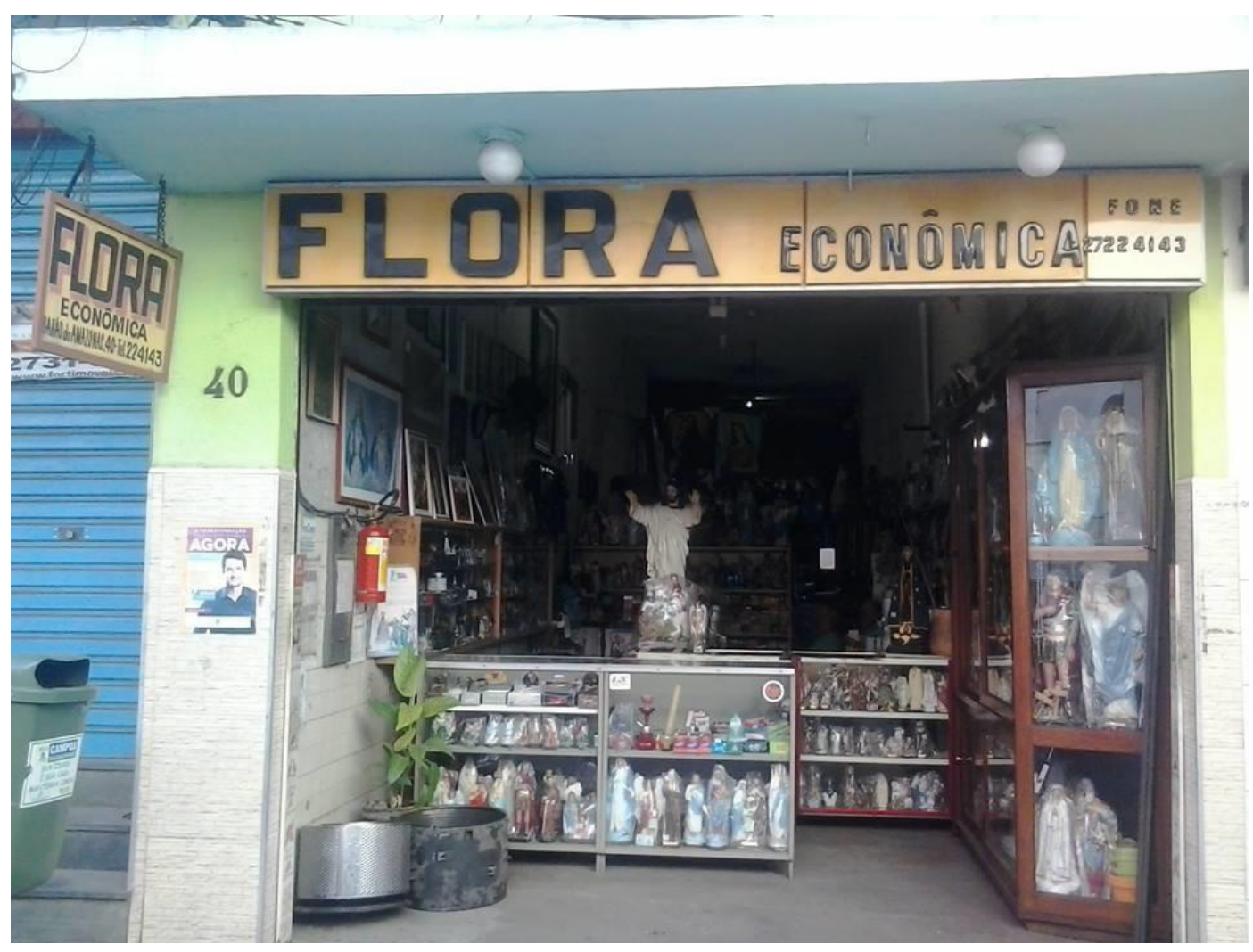

Imagem 06: A loja "Flora Econômica", localizada na rua Barão do Amazonas. Foto: Paula Pimentel 


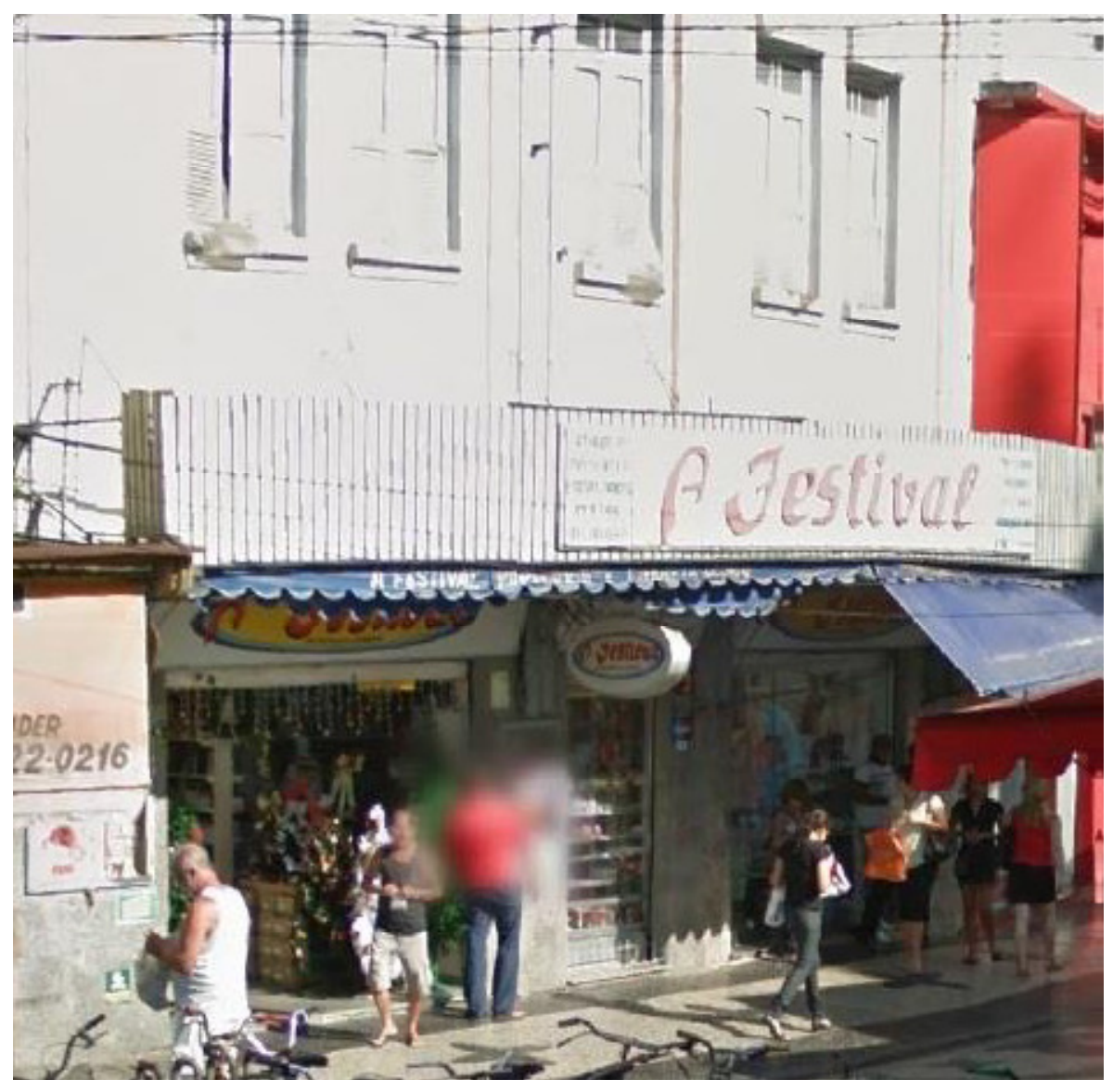

Imagem 07: O prédio da papelaria “A festival”. Fonte: Google maps

Recebido em: Agosto, 2014 Aceito em: Agosto, 2015 


\section{REFERÊNCIAS BIBLIOGRÁFICAS}

ABREU, Regina. Museus, ruínas e paisagens: patrimonialização e disputas de sentidos. In: GUIMARÃES, Maria da Conceição Alves de (Org.). Museografia e Arquitetura de Museus. Rio de Janeiro: UFRJ, FAU, PROARQ, 2010, volume 1, p.190-212.

BERTAUX, Daniel. Los relatos de vida. Barcelona (ESP), Bellaterra, 2005.

ASSIS, R. L. As vulnerabilidades de uma carreira: os camelôs do terminal e a cidade de Campos dos Goytacazes como um espaço de luta por reconhecimento. Dissertação de Mestrado em Sociologia Política. Universidade Estadual do Norte-Fluminense Darcy Ribeiro, 2011.

BECKER, Howard. A história de vida e o mosaico científico. In: Métodos de pesquisa em ciências sociais. São Paulo: Hucitec, 1994.

BENJAMIN, Walter. Paris do Segundo Império. In: Charles Baudelaire: um lírico no auge do capitalismo. Obras escolhidas III. São Paulo: Brasiliense, 2000.

BHABHA, Homi K. O local da cultura. Ed. UFMG: Belo Horizonte, 2005.

CANCLINI, Néstor García. Cidades e cidadãos imaginados pelos meios de comunicação. OPINIÃO PÚBLICA, Campinas, Vol. VIII, n¹, pp.40-53, 2002.

CERTAU, Michel de. A Invenção do Cotidiano. Artes de Fazer. 6a . Petrópolis: Vozes, 1994.

CIFELLI, G. ; PEIXOTO, P. Centros históricos e turismo patrimonial: o pelourinho como exemplo de uma relação contraditória. Sociologia (Porto), v. XXIV, 2012, p. 35-54.

FREITAS, C. R. B. O Mercado Municipal de Campos dos Goytacazes: A sedução persistente de uma instituição pública. Dissertação de mestrado em Políticas Sociais. Universidade Estadual do Norte-Fluminense Darcy Ribeiro, 2006. 
HALBWACHS, Maurice. A memória coletiva. Editora Revista dos Tribunais LTDA, biblioteca vértice, São Paulo, 1990.

HALL, Stuart. A identidade cultural na pós-modernidade. Trad. Tomaz Tadeu da Silva e Guacira Lopes Louro. 7 ed. Rio de Janeiro. DP\&A, 2002.

JACOBS, Jane. Muerte y vida de las grandes ciudades. Madrid: Ediciones Península, 1973. LAMEGO, A. O homem e o brejo. Rio de Janeiro: IBGE, 2007.

MARGEM, Frederico Muylaert.O mapa da migração do capital do setor sucroalcooleiro para o setor de serviços em Campos dos Goytacazes. Dissertação de mestrado em Engenharia de Produção. Universidade Estadual do Norte Fluminense.Fevereiro, 2007.

PARK, R. E. La ciudad y otros ensayos de ecología urbana. Barcelona: Ediciones Del Sebal, 1999.

PESAVENTO, Sandra Jatahy. Cidade, espaço e tempo: reflexões sobre a memória e o patrimônio urbano. Cadernos do LEPAARQ - textos de antropologia, arqueologia e patrimônio, v. II, n.4, Pelotas, RS: editora da UFPEL, ago/dez, 2005.

PIQUET, Rosélia, GIVISIEZ, Gustavo Henrique Naves, DE OLIVEIRA, Elzira Lúcia. A nova centralidade de Campos dos Goytacazes: o velho e o novo no contexto regional. Revista Rio de Janeiro, n. 18-19, jan.-dez 2006.

POLLAK, Michael. Memória e Identidade Social. Estudos Históricos, Rio de Janeiro: vol 5, n 10, p. 200-212, 1992.

ROBERTSON, Roland. Globalização: teoria social e cultura global. Petrópolis, RJ, Vozes, 1999.

ROCHA, Ana Luiza Carvalho da, ECKERT, Cornélia. Antropologia da e na cidade, interpretações sobre as formas da vida urbana. Porto Alegre: Marcavisual, 2013. 
ROCHA, Ana Luiza Carvalho da; ECKERT, Cornélia. Cidade narrada, tempo vivido: estudos de etnografias da duração. RUA [online]. 2010, n.16. Volume 1.

SIMMEL, G. As grandes cidades e a vida do espírito. Coleção: Artigo Lusofia,Universidade da Beira Interior. Covilhã, Portugal, 2009.

VOGEL, A. e MELLO, M. A. da Silva.Quando a rua vira casa, a apropriação de espaços de uso coletivo em um centro de bairro. Rio de Janeiro: IBAM / FINEP, 1981.

VOGEL, Arno e MELLO, M. Antônio da Silva. Sistemas construídos e memória: social: Uma arqueologia urbana? Revista de Arqueologia, Belém, v.2, n.2, p.46-50, 1984.

YÚDICE, George. A Conveniência da Cultura: usos da cultura na era global. Belo Horizonte: Editora UFMG, 2006. 